\title{
Content analysis of resident evaluations of faculty anesthesiologists: supervision encompasses some attributes of the professionalism core competency
} Analyse du contenu de l'évaluation par les résidents des
enseignants en anesthésiologie: la supervision recouvre quelques
attributs du cour de compétence professionnelle

\author{
Franklin Dexter, MD, PhD $•$ Debra Szeluga, MD, PhD • Bradley J. Hindman, MD \\ Received: 31 May 2016/Revised: 15 December 2016/Accepted: 31 January 2017/Published online: 16 February 2017 \\ (C) Canadian Anesthesiologists' Society 2017
}

\begin{abstract}
Background Anesthesiology departments need an instrument with which to assess practicing anesthesiologists' professionalism. The purpose of this retrospective analysis of the content of a cohort of resident evaluations of faculty anesthesiologists was to investigate the relationship between a clinical supervision scale and the multiple attributes of professionalism.

Methods From July 1, 2013 to the present, our department has utilized the de Oliveira Filho unidimensional nine-item supervision scale to assess the quality of clinical supervision of residents provided by our anesthesiologists. The "cohort" we examined included all 13,664 resident evaluations of all faculty anesthesiologists from July 1, 2013 through December 31, 2015, including 1,387 accompanying comments. Words and phrases associated with the core competency of professionalism were obtained from previous studies, and the supervision scale was analyzed for the presence of these words and phrases.
\end{abstract}

Results The supervision scale assesses some attributes of anesthesiologists' professionalism as well as patient care and procedural skills and interpersonal and communication skills. The comments that residents

F. Dexter, MD, PhD - D. Szeluga, MD, PhD

B. J. Hindman, MD

Department of Anesthesia, University of Iowa, Iowa City, IA, USA

F. Dexter, MD, PhD ( $\square)$

Division of Management Consulting, Department of Anesthesia, University of Iowa, 200 Hawkins Drive, 6-JCP, Iowa City,

IA 52242, USA

e-mail: Franklin-Dexter@UIowa.edu

URL: http://www.FranklinDexter.net provided with the below-average supervision scores included attributes of professionalism, although numerous words and phrases related to professionalism were not present in any of the residents' comments.

Conclusions The de Oliveira Filho clinical supervision scale includes some attributes of anesthesiologists' professionalism. The core competency of professionalism, however, is multidimensional, and the supervision scale and/or residents' comments did not address many of the other established attributes of professionalism.

\section{Résumé}

Contexte Les départements d'anesthésiologie ont besoin d'un outil pour évaluer le professionnalisme des anesthésiologistes praticiens. L'objectif de cette analyse rétrospective du contenu des évaluations des enseignants en anesthésiologie par une cohorte de résidents était d'analyser les rapports entre l'échelle de supervision clinique et les multiples attributs du professionnalisme.

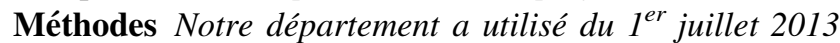
à ce jour l'échelle de supervision unidimensionnelle en neuf points de De Oliveira Filho pour évaluer la qualité de la supervision clinique des résidents assurée par nos anesthésiologistes. La "cohorte»que nous avons examinée incluait la totalité des 13664 évaluations de résidents de tous les anesthésiologistes enseignants $d u$

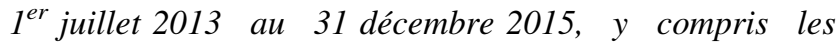
1387 commentaires les accompagnant. Les mots et phrases associés au cour de compétence professionnelle ont été tirés d'études précédentes et l'échelle de supervision a été analysée en recherchant ces mots et phrases.

Résultats L'échelle de supervision évalue certaines caractéristiques du professionnalisme des 
anesthésiologistes de même que les compétences en matière de soins aux patients, de procédures, de communications et de relations interpersonnelles. Les commentaires faits par les résidents avec des notes de supervision inférieures à la moyenne incluaient des caractéristiques de professionnalisme, bien que de nombreux mots et phrases en rapport avec le professionnalisme n'aient pas été retrouvés dans les commentaires des résidents.

Conclusions L'échelle de supervision clinique de De Oliveira Filho inclut quelques caractéristiques $d u$ professionnalisme des anesthésiologistes. Néanmoins, la compétence centrale du professionnalisme est multidimensionnelle et l'échelle de supervision et/ou les commentaires des résidents n'ont pas abordé un grand nombre des autres caractéristiques connues $d u$ professionnalisme.

In the United States, anesthesia departments are required to provide the hospitals with physician-specific metrics that demonstrate competence in their professional practice in order for the physicians to maintain hospital privileges. ${ }^{1}$ The Joint Commission refers to the process as "Ongoing Professional Practice Evaluation" (OPPE). ${ }^{1}$ Six core competencies $^{2}$ are often used as a framework for OPPE assessment. " A competency is said to be a "core" competency when it applies to every physician, regardless of medical specialty. The core competencies include patient care and procedural skills, interpersonal and communication skills, and professionalism. ${ }^{\mathrm{A}}$ The recent review article by Yang addressing professionalism in anesthesia emphasized that feedback is essential to improve professionalism, whether in "the form of annual reappointment assessments, peer assessments, $360^{\circ}$ evaluations," and so on. ${ }^{3}$ A limitation, however, is that none of these areas is measured on a specific scale (instrument). Thus, the development of a reliable, valid way to assess anesthesiologists' professionalism is needed. ${ }^{4}$

Many anesthesiologists working in operating rooms and other procedural locations (henceforth referred to as "ORs") provide clinical supervision (e.g., generally with anesthesia residents and, in the United States, nurse anesthetists). ${ }^{5,6}$ "Supervision" entails clinical oversight functions directed toward ensuring the quality of clinical care whenever the anesthesiologist is not the sole anesthesia care provider. When the anesthesiologist is supervising an OR, depending

\footnotetext{
$\overline{\mathrm{A}}$ The other three core competencies - practice-based learning and improvement, systems-based practice, medical knowledge - were not included in this article.
}

on other responsibilities - such as in another OR and/or a post-anesthesia care unit - it can be challenging to be present at critical portions of every anesthetic delivery and still contribute fully to each patient's care. ${ }^{5,7-9}$ Thus, our department monitors the quality of anesthesiologists' supervision and provides them with periodic feedback. 5,10

Individual faculty anesthesiologists can be reliably and dependably assessed using the de Oliveira Filho nine-item clinical supervision scale (Table 1). ${ }^{11-13}$ Low supervision scores have been associated with resident reports of increased errors with adverse effects on patients. ${ }^{14-16}$ The nine-item scale was designed to measure all attributes of faculty anesthesiologists' supervision of anesthesia residents (Table 1). The scale has repeatedly been shown in multiple studies to do so as a unidimensional construct (including assessments by nurse anesthetists). ${ }^{13,15,17,18}$ Along with the daily numerical scores of faculty supervision, our residents may also provide a written free-text comment about the faculty anesthesiologist. ${ }^{18}$ The supervision scores and comments are the cumulative result of how the anesthesiologists perform in clinical environments (i.e., they reflect in situ performance and improve with feedback). ${ }^{6,10,17}$

In the current study, we performed a content analysis of a cohort of our department's residents' written evaluations of faculty anesthesiologists to test two hypotheses. One hypothesis was that the clinical supervision scale includes attributes of professionalism and thus is in part assessing anesthesiologists' professionalism. The basis for our hypothesis was that de Oliveira Filho et al. labelled their question \#4 (Table 1) as a reflection of "professionalism."17 Our second hypothesis was that professionalism has other attributes not measured by the supervision scale and not reported by our residents (i.e., supervision and professionalism are not equivalent constructs). The basis for our hypothesis was that previous studies have listed words and phrases associated with professionalism but seemingly of different themes (Tables 2-4). ${ }^{2,19-23}$

\section{Methods}

The University of Iowa Institutional Review Board declared (November 9, 2015) that this investigation did not meet the regulatory definition of human subjects research. All analyses were performed with de-identified data.

From July 1, 2013 to the present, our department has utilized the de Oliveira Filho supervision scale ${ }^{6,10-17}$ to assess the quality of clinical supervision provided by our anesthesiologists (Table 1). The cohort reported herein included all of the residents' evaluations of all faculty anesthesiologists over the 2.5-year period, from the starting 
Table 1 de Oliveira Filho Scale ${ }^{17}$ for Measuring Faculty Anesthesiologists' Supervision of Residents During Clinical Operating Room Care

1. The faculty provided me timely, informal, nonthreatening comments on my performance and showed me ways to improve

2. The faculty was promptly available to help me solve problems with patients and procedures

3. The faculty used real clinical scenarios to stimulate my clinical reasoning, critical thinking and theoretical learning

4. The faculty demonstrated theoretical knowledge, proficiency at procedures, ethical behaviour, and interest/compassion/respect for patients

5. The faculty was present during the critical moments of the anesthetic procedure (e.g., anesthesia induction, critical events, complications)

6. The faculty discussed with me the perianesthesia management of patients prior to starting an anesthetic procedure and accepted my suggestions, when appropriate

7. The faculty taught and demanded the implementation of safety measures during the perioperative period (e.g., anesthesia machine checkout, universal precautions, prevention of medication errors, etc.)

8. The faculty treated me respectfully, and strived to create and maintain a pleasant environment during my clinical activities

9. The faculty gave me opportunities to perform procedures and encouraged my professional autonomy

The uniquely selectable choices beneath each question were: 1-never; 2-rarely; 3-frequently; or 4-always. All questions were presented daily in the same sequence. The wording differs from that developed ${ }^{17}$ only to the extent that (a) the word "faculty" was used instead of "instructor" to be more closely aligned with the role of supervision of the nurse anesthetists and (b) the tense of the verbs was changed to past tense because each evaluation was for a specific date working together

Table 2 Words and Phrases in the Quality of Supervision Scale and their Association with Professionalism and other Competencies

\begin{tabular}{|c|c|c|}
\hline de Oliveira Filho Supervision Scale Word or Phrase & $\begin{array}{l}\text { Potential Association with Other Core } \\
\text { Competencies }^{2}\end{array}$ & $\begin{array}{l}\text { References for Association with } \\
\text { Professionalism }\end{array}$ \\
\hline timely, informal, nonthreatening comments & interpersonal and communication skills & 20,22 \\
\hline showed me ways to improve & & 20 \\
\hline $\begin{array}{l}\text { promptly available to help me solve problems with } \\
\text { patients }\end{array}$ & & 20,21 \\
\hline $\begin{array}{l}\text { demonstrated theoretical knowledge and proficiency at } \\
\text { procedures }\end{array}$ & patient care and procedural skills & 19,22 \\
\hline ethical behaviour & & $19,20,23$ \\
\hline interest/compassion/respect for patients & & $2,19-23$ \\
\hline present during the critical moments & patient care and procedural skills & 21 \\
\hline $\begin{array}{l}\text { discussed with me the peri-anesthesia management } \\
\text { accepted my suggestions, when appropriate }\end{array}$ & $\begin{array}{l}\text { interpersonal and communication skills } \\
\text { patient care and procedural skills }\end{array}$ & 20 \\
\hline $\begin{array}{l}\text { taught and demanded the implementation of safety } \\
\text { measures }\end{array}$ & patient care and procedural skills & $19,21,22$ \\
\hline treated me respectfully & interpersonal and communication skills & $2,19,20,22$ \\
\hline maintain a pleasant environment & & 19,20 \\
\hline gave me opportunities to perform procedures & patient care and procedural skills & \\
\hline
\end{tabular}

Phrases are listed in sequence of the questions as presented in studies. In the Reference (2), see also section IV.A.5.a).(2) starting on page 15 for "patient care and precedural skills." As an example of application of the column 3 references, we consider the 2 rows for which Reference (2) has been listed: "interest/compassion/respect for patients" and "treated me respectfully." From the reference, "residents are expected to demonstrate," "compassion, integrity, and respect for others," "responsiveness to patient needs that supersedes self-interest," and "respect for patient privacy and autonomy"

date of July 1, 2013 through December 31, 2015; the study was initiated February 2016 (see Discussion newsletter article). The evaluation process consisted of daily, automated e-mail requests ${ }^{24}$ to anesthesia residents to evaluate the supervision provided by each anesthesiologist with whom they worked the previous day in an OR setting, including obstetrics and/or nonoperating room anesthesia (e.g., radiation therapy). ${ }^{6,10-12,18}$ The residents provided numerical scores to answer the scale's nine questions (Table 1). The 13,664 numerical evaluations were supplemented with 1387 free-text comments. ${ }^{\mathrm{B}}$ Comments and scores are confidential, with scores provided only after averaging. Comments were never provided directly to the individual anesthesiologist

\footnotetext{
B Among the 14,722 evaluations that were requested, residents provided a response for $99.1 \%(n=14,585)$. Residents could answer that they worked with the faculty that day for insufficient time to evaluate the supervision. Residents used this option for $6.3 \%$ of requests $(\mathrm{N}=921)$. Among the $\mathrm{n}=13,664$ numerical evaluations of supervision quality, the mean supervision score was 3.80 with a standard deviation of 0.37 , with $2.20 \%$ less than "frequent" (i.e., $<$ 3.00). These values were reported in an earlier paper of ours, in the first paragraph of the Results of Reference section. ${ }^{18}$
} 
because their usefulness depended on the procedural context, which often revealed the identity of the evaluating resident. ${ }^{10,18,25,26}$

Comments were searched automatically using Excel 2010 (Microsoft Corp., Redmond, WA, USA) for the presence or absence of words associated with physicians' professionalism, without regard to capitalization. ${ }^{18}$ Words and phrases (Tables 2-4) associated with professionalism were obtained from the Accreditation Council for Graduate Medical Education's Program Requirements for Anesthesiology and from previous studies. ${ }^{2,19-23}$ For testing the hypotheses, the words and phrases needed to represent attributes of professionalism. Tables 2-4 show these attributes and their corresponding references. The right-most columns of Tables 2-4 with the head "references for association with professionalism" were completed independently by each of this article's authors to ensure an absence of coding error. Only words and phrases with concordance among the authors as being in a reference were included in Tables 2-4. This method was suitable for testing the hypotheses because the words and phrases needed not (and do not) represent a complete set of the attributes of professionalism. The hypotheses are deterministic (i.e., not based on "average," "most," and so on) and thus are not tested inferentially. The hypotheses are, however, potentially sensitive to a few words, and to residents, and/or faculty. Therefore, counts of each of these categories are included as sensitivity analyses.

\section{Results}

Table 2 shows that the nine-item supervision scale assesses some attributes of professionalism. There are eight "words or phrases" pertaining to professionalism. Table 3 contains examples of words and phrases that (a) residents provided with below-average supervision scores and (b) are related to professionalism. The 17 words or phrases (made by 11 residents) pertaining to professionalism are from 18 comments obtained on 18 different dates in regard to 14 anesthesiologists. Together, Tables 2 and 3 show that the unidimensional construct of clinical supervision has attributes in common with professionalism. Based on the findings of Tables 2 and 3, our hypothesis was satisfied and was insensitive to exclusion of specific dates, anesthesiologists, or residents.

In contrast, Table 4 contains 68 words and phrases related to professionalism that are present in zero (i.e., none) of the residents' 1,387 comments (i.e., the comments associated with any score, low or high). Notably, this zero tally represented the absence of these words and phrases over the course of 13,664 evaluations, on 581 dates, by
Table 3 Words and Phrases Associated with Professionalism and Present in the 215 Resident Comments with Below Average Rating of Faculty Quality of Supervision

\begin{tabular}{lll}
\hline $\begin{array}{l}\text { Comment Word or } \\
\text { Phrase about } \\
\text { Anesthesiologist }\end{array}$ & $\begin{array}{l}\text { Count of } \\
\text { Evaluations } \\
\text { (Comments) }\end{array}$ & $\begin{array}{l}\text { References for } \\
\text { Association with } \\
\text { Professionalism }\end{array}$ \\
\hline belligerent & 1 & 20,21 \\
completely disrespectful & 1 & $2,20-22$ \\
condescending attitude & 1 & 20 \\
condescending remarks & 1 & 20 \\
confrontational & 1 & 20,21 \\
demeaning & 4 & 20,21 \\
disrespectful and abrasive & 1 & $2,20-22$ \\
disruptive & 1 & $20-22$ \\
hostile & 2 & $20-22$ \\
mocking of resident work & 1 & 20 \\
refuses to explain & 1 & 20 \\
rude & 2 & 20,22 \\
yelled rather than taught & 1 & 20 \\
did not respond to my pages & 1 & $2,20,21$ \\
I did not see & 2 & 20,21 \\
not even always staying in the unit & 1 & 20,21 \\
spends < 5 min & 1 & 20,21 \\
\hline All of the comments in & &
\end{tabular}

All of the comments in this table were published previously in Tables 3-4 of Reference (18). What is new is the application and the 3rd column

The words and phrases in this Table 3 appeared among the 215 of 1,387 comments accompanying a below-average daily supervision score. There was only one occurrence of the words and phrases among the other 1,172 comments. ${ }^{18}$ "Demeaning" appeared once, and with negation: "was not demeaning"18

The following are some of the quantitative results from Reference (18). The mean (standard deviation [SD]) supervision scores for the 25 evaluations with a comment about the anesthesiologist being disrespectful were less than for the other 1,362 evaluations with comments [2.86 (0.65) vs 3.90 (0.27); $P<0.001)$. Each increase in the faculty's number of comments of being disrespectful (from 0 to 5) was associated with a lesser mean score (Kendall's $\tau_{\mathrm{b}}=-0.31$, $P<0.001)$. A low supervision score $(<3.00)$ had an odds ratio of 85.4 (95\% confidence interval, 31.2 to 232.5 ) for a comment regarding disrespectful faculty behaviour $(P<0.001)$. The six faculty who each had a comment about insufficient faculty presence had significantly lesser mean (SD) scores than the other 70 faculty $[3.70(0.09)$ vs $3.81(0.12) ; P=0.007)$. The six evaluations with comments related to insufficient faculty presence had lesser mean (SD) scores than the other 1,381 evaluations with comments [2.61 (0.30) vs 3.89 (0.30); $P<0.001)$

90 anesthesiologists and 59 residents. Consequently, Table 4 shows that multiple attributes of professionalism are not elements of the clinical supervision scale. Thus, our second hypothesis also was satisfied - a result that also was insensitive to specific exclusion of dates, anesthesiologists, or residents. 
Table 4 Words and Phrases Associated with Professionalism and Not Present in the Quality of Supervision Scale Questions ${ }^{17}$ or in any of the Residents' 1,387 Positive or Negative Comments Made While Evaluating the Faculty

\begin{tabular}{|c|c|}
\hline Word or Phrase & $\begin{array}{l}\text { References for Association } \\
\text { with Professionalism }\end{array}$ \\
\hline accepts criticism & 23 \\
\hline accepts responsibility & $19,21,23$ \\
\hline accountability & $19,20,22,23$ \\
\hline accountable & $19,20,22,23$ \\
\hline accurate records & 20 \\
\hline advocacy & $19,20,22,23$ \\
\hline altruism & $19,21,22$ \\
\hline altruistic & 19,21 \\
\hline biased & 21 \\
\hline civilized & 22 \\
\hline collaborate & $19-21$ \\
\hline collaborative & $19-21$ \\
\hline collaboratively & $19-21$ \\
\hline competent & 19,22 \\
\hline confidential & $2,19-21,23$ \\
\hline confidentiality & $2,19-21,23$ \\
\hline conflict of interest & 19 \\
\hline cost effective & 19 \\
\hline cost-effective & 19 \\
\hline cultural diversity & $2,19,20$ \\
\hline cutting corners & 22 \\
\hline dignity & 23 \\
\hline disclose & 19,21 \\
\hline disclosure & $19,21,22$ \\
\hline discriminates & 19,21 \\
\hline discrimination & 19,21 \\
\hline discriminatory & 19,21 \\
\hline dishonest & 19,21 \\
\hline empathetic & 21 \\
\hline empathy & $20,21,23$ \\
\hline equitable & 19 \\
\hline exploit & 19 \\
\hline fairness & 19 \\
\hline honest & 19,23 \\
\hline honesty & $19,22,23$ \\
\hline information to patients & 19,20 \\
\hline integrity & $2,19,20,22,23$ \\
\hline interest of the patient & 19 \\
\hline justice & 19,21 \\
\hline mastery & 22 \\
\hline maturity & 23 \\
\hline morality & 22 \\
\hline obstructive & 22 \\
\hline patient autonomy & $2,19-21$ \\
\hline patients' autonomy & $2,19-21$ \\
\hline
\end{tabular}

Table 4 continued

\begin{tabular}{ll}
\hline Word or Phrase & $\begin{array}{l}\text { References for Association } \\
\text { with Professionalism }\end{array}$ \\
\hline patient's autonomy & $2,19-21$ \\
patient centered & 19,21 \\
patient-centered & 19,21 \\
patient decision making & 19,21 \\
patient decision-making & 19,21 \\
patients' dignity & 20,22 \\
patient's dignity & 20,22 \\
patient interest & 19,21 \\
patients' interest & 19,21 \\
patient's interest & 19,21 \\
professional competence & 19 \\
responsible & $19,21,22$ \\
self-assessment & 22 \\
self-awareness & 22,23 \\
self interest & 19 \\
self-interest & 19 \\
shared decision making & 19,21 \\
shared decision-making & 19,21 \\
swearing & 20,22 \\
takes responsibility & 19,22 \\
timeliness of charting & 21 \\
trustworthy & 19,23 \\
welfare & 19,21 \\
\hline
\end{tabular}

To indicate the importance of the references other than that one of the Accreditation Council for Graduate Medical Education Program Requirements for Graduate Medical Education in Anesthesiology, ${ }^{2}$ reference 2 is listed in the second column for just seven of the 68 rows

\section{Discussion}

Our content analysis was motivated by a newsletter article from the Anesthesia Quality Institute Anesthesia Incident Reporting System Steering Committee, "Professionalism: Will we know it when we see it?"21 The article discussed a case report from an anesthesia incident-reporting system that described an event related, in part, to inadequate faculty supervision of an anesthesia resident. Specifically, there was insufficient faculty presence - an attribute of professionalism associated with low supervision scores (Table 3). ${ }^{13,18}$ There was concern regarding the resident's honesty, another attribute of professionalism (Table 4). ${ }^{21}$ There was poor interpersonal communication (a core competency distinct from professionalism) between the resident and the faculty anesthesiologist, which may have contributed to the event. Thus, we had reason to expect that the supervision scale encompasses more than one of the six core competencies $^{2}$ (Table 2) and that professionalism includes not only the dimension of 
supervision (Tables 2 and 3) but other attributes as well (Table 4) - i.e., the core competency of professionalism is multidimensional. Our results show that our conclusion holds. The conclusion matches that of Symons et al. in which factor analysis of family practice residents' selfassessments identified two dimensions of professionalism: "interpersonal relations" and "conveying medical information [to patients]." 27

The data in Tables 2 and 3 show that the conclusions are not self-evident. Regarding the implication that professionalism includes the dimension of supervision, three articles about professionalism in anesthesiology lacked the word "supervision," 3,22,23 including the review by Yang. $^{3}$ Regarding the implication that the clinical supervision scale assesses anesthesiologists' professionalism, our earlier article, showing that supervision scores were sufficient to identify anesthesiologists with disrespectful behaviour, did not include the word "professionalism." 18 Although de Oliveira Filho et al. labelled their question \#4 (Table 1) "professionalism," they did not show that it was measuring professionalism. We think that question \#4's three phrases assess professionalism, but so do eight other phrases in the supervision scale (Table 2).

We considered attributes of professionalism in clinical practice as it relates to maintenance of clinical privileges and OPPE. However, there are other attributes of professionalism. For example, among medical students and resident physicians, unprofessional behaviours include cheating, misrepresentation of publications, plagiarism, and falsification of documentation such as work hours. ${ }^{4}$ The addition of such words and phrases to Table 4 for these behaviours would have strengthened our finding that the constructs of "supervision" and "professionalism" are not equivalent, despite their extensive overlap of attributes (Tables 2 and 3).

Some of the attributes of professionalism in Table 4 may be unimportant to the residents and, hence, were not "worthy" of a comment. ${ }^{28}$ Alternatively, and we think more likely, during the course of their daily interaction in the OR with an anesthesiologist, anesthesia residents would not know if these attributes were present in their faculty. For example, we speculated that residents would care if the anesthesiologist violated the patient's confidentiality (Table 4), in part because the faculty anesthesiologist's patient is also the resident's patient. However, it would be unlikely that the resident would know that a breach of confidentiality occurred because usually such an event occurs outside the OR. Thus, although Tables 2 and 3 show that residents' daily assessments of faculty clinical supervision measure some attributes of professionalism, Table 4 shows that our residents' assessments of the anesthesiologists' professionalism are incomplete. There are two implications of these findings. Whereas less than frequent supervision ${ }^{10,29}$ shows unprofessional behaviour, it is entirely possible for an anesthesiologist to exhibit unprofessional behaviours and yet provide consistently high-quality supervision. Therefore, in addition to supervision scores and comments, other methods/metrics are necessary for full assessment of anesthesiologists' professionalism.

To demonstrate competence in professional practice suitable for maintaining clinical privileges (i.e., OPPE), our department assesses and reports physician-specific practice metrics. ${ }^{1}$ Although the supervision scale includes several attributes of professionalism (Tables 2 and 3), it excludes many others (Table 4). For OPPE reporting, ${ }^{1}$ our department's metrics also include (a) faculty completion rates for trainee evaluations over six-month periods and (b) faculty completion rates of anesthesia record attestations within six days after the date of service, also over the six-month periods. These additional metrics assess the professionalism measures of maintaining accurate records and being accountable (Table 4).

Tables 2 and 3 show that the supervision scale ${ }^{6,10-17}$ assesses three of the six core competencies to be assessed and reported: professionalism, interpersonal and communication skills, and patient care and procedural skills. Validity of its assessment of the competency of patient care and procedural skills is based also on the supervision scores being correlated with the raters' choice of the anesthesiologist to care for their family. ${ }^{11}$ The supervision scale is a measure of an anesthesiologist's individual contribution to the department, statistically independent of clinical production, specifically weekly anesthesia hours. ${ }^{6}$ The supervision scale also quantifies faculty anesthesiologists' quality of clinical teaching. ${ }^{18}$ These multiple roles for the supervision scale are not obtained because the supervision scale is multidimensional. In fact, it has been found in multiple departments and settings to be unidimensional (Cronbach $\alpha=0.948) .{ }^{11,13,15,17,18}$ Rather, it is because the core competencies, ${ }^{2}$ as well as clinical teaching, do not themselves represent distinct (i.e., separable) dimensions for assessment.

In conclusion, although the de Oliveira Filho clinical supervision scale includes some attributes of anesthesiologists' professionalism. However, the core competency of professionalism is multidimensional. Thus, many attributes of professionalism were not addressed by the supervision scale and/or were not included in the residents' comments.

Acknowledgements Ms. Jennifer Espy provided editorial assistance. Mr. Thomas Smith managed the department database and web interfaces. 
Conflicts of interest None declared.

Editorial responsibility This submission was handled by Dr. Hilary P. Grocott, Editor-in-Chief, Canadian Journal of Anesthesia.

Author contributions Franklin Dexter helped design the study, conduct the study, analyze the data, and write the manuscript. Debra Szeluga helped conduct the study. Bradley J. Hindman helped conduct the study and write the manuscript. All authors have seen the original study data and approved the final manuscript.

Funding Departmental funding.

\section{References}

1. The Joint Commission. Standards BoosterPak for Focused Professional Practice Evaluation/ Ongoing Professional Practice Evaluation (FPPE/OPPE). Updated March 2013. Available from URL: http://www.mc.vanderbilt.edu/documents/nursingoap/files/ Joint \% 20Commission\%20Booster\%20Pack\%20BP_FPPEOPPE\%20Updated\%20March\%202013.pdf (accessed December 2016).

2. Accreditation Council for Graduate Medical Education. ACGME Program Requirements for Graduate Medical Education in Anesthesiology, Section IV.A.5.e "Professionalism," page 19. Available from URL: http://www.acgme.org/Portals/0/PFAssets/ ProgramRequirements/040_anesthesiology_2016.pdf (accessed December 2016).

3. Yang H. Professionalism in anesthesia. Can J Anesth 2017; 64: 149-57.

4. Fargen KM, Drolet BC, Philibert I. Unprofessional behaviors among tomorrow's physicians: review of the literature with a focus on risk factors, temporal trends, and future directions. Acad Med 2016; 91: 858-64.

5. Epstein RH, Dexter F. Influence of supervision ratios by anesthesiologists on first-case starts and critical portions of anesthetics. Anesthesiology 2012; 116: 683-91.

6. Dexter F, Hindman BJ. Quality of supervision as an independent contributor to an anesthesiologist's individual clinical value. Anesth Analg 2015; 121: 507-13.

7. Smallman B, Dexter F, Masursky D, et al. Role of communication systems in coordinating supervising anesthesiologists' activities outside of operating rooms. Anesth Analg 2013; 116: 898-903.

8. Rothman BS, Ehrenfeld JM. Paging doctor, emergency? Anesth Analg 2014; 119: 4-6.

9. Warner ME, Chong EY, Lowe ME, Sprung J, Weingarten TN. Emergency pages using a computer-based anesthesiology paging system in ambulatory surgical centers: a retrospective review. Anesth Analg 2014; 119: 145-50.

10. Dexter $F$, Ledolter J, Hindman BJ. Bernoulli cumulative sum (CUSUM) control charts for monitoring of anesthesiologists' performance in supervising anesthesia residents and nurse anesthetists. Anesth Analg 2014; 119: 679-85.

11. Hindman BJ, Dexter F, Kreiter CD, Wachtel RE. Determinants, associations, and psychometric properties of resident assessments of anesthesiologist operating room supervision. Anesth Analg 2013; 116: 1342-51.

12. Dexter F, Ledolter J, Smith TC, Griffiths D, Hindman BJ. Influence of provider type (nurse anesthetist or resident physician), staff assignments, and other covariates on daily evaluations of anesthesiologists' quality of supervision. Anesth Analg 2014; 119: 670-8.

13. Dexter F, Masursky D, Hindman BJ. Reliability and validity of the anesthesiologist supervision instrument when certified registered nurse anesthetists provide scores. Anesth Analg 2015; 120: 214-9.

14. De Oliveira GS, Jr Rahmani R, Fitzgerald PC, Chang $R$, $M c$ Carthy RJ. The association between frequency of self-reported medical errors and anesthesia trainee supervision: a survey of United States anesthesiology residents-in-training. Anesth Analg 2013; 116: 892-7.

15. De Oliveira GS, Jr Dexter F, Bialek JM, McCarthy RJ. Reliability and validity of assessing subspecialty level of faculty anesthesiologists' supervision of anesthesiology residents. Anesth Analg 2015; 120: 209-13.

16. Hindman BJ, Dexter F, Smith TC. Anesthesia residents' global (departmental) evaluation of faculty anesthesiologists' supervision can be less than their average evaluations of individual anesthesiologists. Anesth Analg 2015; 120: 204-8.

17. de Oliveira Filho GR, Dal Mago AJ, Garcia JH, Goldschmidt R. An instrument designed for faculty supervision evaluation by anesthesia residents and its psychometric properties. Anesth Analg 2008; 107: 1316-22.

18. Dexter F, Szeluga D, Masursky D, Hindman BJ. Written comments made by anesthesia residents when providing below average scores for the supervision provided by the faculty anesthesiologist. Anesth Analg 2016; 122: 2000-6.

19. Teplick SK, Berlin L, Cascade PN, et al. Medical professionalism in the new millennium: a physicians' charter. Radiology 2006; 238: $383-6$

20. Todhunter S, Cruess SR, Cruess RL, Young M, Steinert Y. Developing and piloting a form for student assessment of faculty professionalism. Adv Health Sci Educ Theory Pract 2011; 16: $223-38$.

21. Anesthesia Quality Institute Anesthesia Incident Reporting System Steering Committee. Professionalism: Will we know it when we see it? ASA Monitor 2016; 80: 24-6.

22. Bahaziq W, Crosby E. Physician professional behaviour affects outcomes: a framework for teaching professionalism during anesthesia residency. Can J Anesth 2011; 58: 1039-50.

23. Kearney $R A$. Defining professionalism in anaesthesiology. Med Educ 2005; 39: 769-76.

24. Epstein RH, Dexter F, Patel $N$. Influencing anesthesia provider behavior using anesthesia information management system data for near real-time alerts and post hoc reports. Anesth Analg 2015; 121: 678-92.

25. Dexter F, Ledolter J, Hindman BJ. Quantifying the diversity and similarity of surgical procedures among hospitals and anesthesia providers. Anesth Analg 2016; 122: 251-63.

26. O'Neill L, Dexter $F$, Zhang $N$. The risks to patient privacy from publishing data from clinical anesthesia studies. Anesth Analg 2016; 122: 2017-27.

27. Symons AB, Swanson A, McGuigan D, Orrange S, Akl EA. A tool for self-assessment of communication skills and professionalism in residents. BMC Med Educ 2009; 9: 1.

28. Dexter F, Masursky D, Szeluga D, Hindman BJ. Work habits are valid component of evaluations of anesthesia residents based on faculty anesthesiologists' daily written comments about residents. Anesth Analg 2016; 122: 1625-33.

29. Dexter F, Logvinov II, Brull SJ. Anesthesiology residents' and nurse anesthetists' perceptions of effective clinical faculty supervision by anesthesiologists. Anesth Analg 2013; 116: $1352-5$. 